Published in final edited form as:

JMed Chem. 2019 September 12; 62(17): 8330-8337. doi:10.1021/acs.jmedchem.9b01192.

\title{
4,8-Dimethylcoumarin Inhibitors of Intestinal Anion Exchanger slc26a3 (Downregulated in Adenoma) for Anti-Absorptive Therapy of Constipation
}

\author{
Sujin Lee ${ }^{\dagger}$, Onur Cil ${ }^{\dagger, \ddagger}$, Peter M. Haggie ${ }^{\dagger}$, Alan S. Verkman ${ }^{\star}, \dagger, \S$ \\ tDepartment of Medicine, University of California, San Francisco, San Francisco, California \\ 94143-0521, United States \\ ‡Department of Pediatrics, University of California, San Francisco, San Francisco, California \\ 94143-0521, United States \\ $\S$ Department of Physiology, University of California, San Francisco, San Francisco, California \\ 94143-0521, United States
}

\begin{abstract}
The chloride/bicarbonate exchanger SLC26A3 (downregulated in adenoma) is expressed mainly in colonic epithelium, where it dehydrates the stool by facilitating the final step of chloride and fluid absorption. SLC26A3 inhibition has predicted efficacy in various types of constipation including that associated with cystic fibrosis. We previously identified, by high-throughput screening, 4,8dimethylcoumarin inhibitors of murine slc26a 3 with $\mathrm{IC}_{50}$ down to $\sim 150 \mathrm{nM}$. Here, we synthesized a focused library of forty-three 4,8-dimethylcoumarin analogues. Structure-activity studies revealed the requirement of 4,8-dimethylcoumarin-3-acetic acid for activity. The most potent inhibitors were produced by replacements at $\mathrm{C} 7$, including 3-iodo- (4az) and 3-trifluoromethyl(4be), with $\mathrm{IC}_{50}$ of 40 and $25 \mathrm{nM}$, respectively. Pharmacokinetics in mice showed predicted therapeutic concentrations of $\mathbf{4 a z}$ for $>72 \mathrm{~h}$ following a single $10 \mathrm{mg} / \mathrm{kg}$ oral dose. $\mathbf{4 a z}$ at 10 $\mathrm{mg} / \mathrm{kg}$ fully normalized stool water content in a loperamide-induced mouse model of constipation. The favorable inhibition potency, selectivity within the SLC26 family, and pharmacological properties of $\mathbf{4 a z}$ support its further preclinical development.
\end{abstract}

\section{Graphical Abstract}

\footnotetext{
*Corresponding Author Alan.Verkman@ucsf.edu. Phone: 415-476-8530. Fax: 415-665-3847.

Author Contributions

S.L. performed synthesis and compound analysis, some transport assays, and LC/MS for pharmacokinetic analysis. O.C. performed murine constipation and pharmacokinetic studies. P.M.H. performed some transport assays. All authors designed experiments, analyzed data, and wrote the manuscript. O.C., P.M.H. and A.S.V. developed the original concept for this study.

The authors declare the following competing financial interest(s): OC, PMH, and ASV are named coinventors on a provisional patent application filed April 2018 whose rights are owned by UCSF.

Supporting Information

The Supporting Information is available free of charge on the ACS Publications website at DOI: 10.1021/acs.jmedchem.9b01192. Structures of commercial slc26a3 inhibitors, and synthesis details, and spectroscopic characterization of new molecules (PDF) Molecular strings and data for all final inhibitor candidates (CSV)
} 


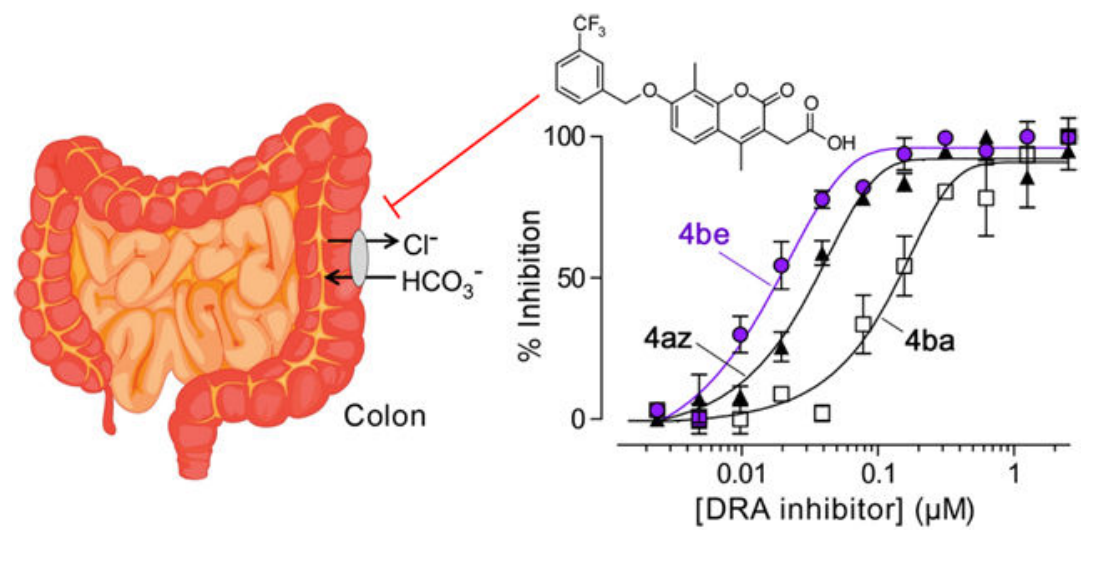

\section{INTRODUCTION}

Constipation is a common clinical problem affecting $\sim 15 \%$ of the US population, ${ }^{1}$ with at least 3-fold greater prevalence in cystic fibrosis (CF) because of impaired function of the pro-secretory chloride channel CF transmembrane conductance regulator (CFTR) in the intestine. ${ }^{2}$ Currently available treatments for chronic constipation include dietary and lifestyle changes, over-the-counter medications such as osmotic and stimulant laxatives, and FDA-approved prescription drugs that stimulate intestinal fluid secretion. ${ }^{3,4}$ The approved pro-secretory drugs lubiprostone, linaclotide, and plecanatide activate CFTR and perhaps apical membrane chloride channels indirectly and show limited efficacy in clinical trials. ${ }^{4}$ These drugs are unlikely to be effective in CF because they primarily rely on functional CFTR. We recently identified activators of wild-type CFTR with pro-secretory action that showed greater efficacy than lubiprostone and linaclotide in mouse models of constipation. 5,6 The CFTR activators, as expected, were not effective in CF mice lacking functional CFTR. An alternative approach for increasing stool hydration in constipation is inhibition of intestinal fluid absorption. Tenapanor, an inhibitor of the sodium-hydrogen exchanger 3 in small intestine and proximal colon, ${ }^{7}$ recently completed a phase 3 clinical trial for constipation predominant irritable bowel syndrome, showing limited efficacy, ${ }^{4}$ perhaps due to intact fluid absorption in more distal parts of the intestine. There remains an unmet need for more efficacious anti-constipation drugs with alternative mechanisms of action for the general population and particularly for CF subjects.

The SLC26A3 protein, originally named downregulated in adenoma (DRA), is a chloride/ anion exchanger expressed most strongly at the luminal plasma membrane of intestinal epithelial cells in colon. ${ }^{7-9}$ On the basis of the finding that loss-of-function mutations in SLC26A3 in humans cause chloride-losing diarrhea, ${ }^{10}$ as does slc26a3 knockout in mice, ${ }^{11}$ SLC26A3 inhibition, by reducing colonic fluid absorption and thus blocking the terminal step of stool dehydration, is predicted to be effective as an anti-absorptive therapy for all forms of constipation, including that associated with CF.

Using a cell-based high-throughput screen, we recently identified 4,8-dimethylcoumarin inhibitors of the slc26a3 anion exchanger. ${ }^{12}$ The most potent compound was 4,8-dimethyl-7(m-bromobenzyloxy)-coumarin-3-acetic acid 4ba, which reversibly inhibited SLC26A3- 
mediated anion transport with $\mathrm{IC}_{50} \approx 150 \mathrm{nM}$ and showed efficacy in a mouse model of constipation. Here, following an initial analysis of 176 commercially available analogues of the originally identified inhibitors, we synthesized a focused library of forty-three 4,8dimethylcoumarin analogues, which included compounds that inhibited slc26a 3 selectively with $\mathrm{IC}_{50}$ down to $25 \mathrm{nM}$ and had favorable pharmacological properties and efficacy in an experimental mouse model of constipation.

\section{RESULTS}

\section{Preliminary Structure-Activity Relationship Analysis.}

Initially, 176 commercially available coumarin analogues of our originally reported inhibitor 4ba $\left(\right.$ DRA $_{\text {inh }}$-A250) were tested. ${ }^{12}$ The structure-activity relationship (SAR) revealed the requirement of methyl substitution at $\mathrm{C} 4$ and $\mathrm{C} 8$, and an acetic acid moiety at $\mathrm{C} 3$, with $\mathrm{C} 7$ substituents producing a wide range of activity. Of 80 compounds purchased with different C7 substituents (representative compounds shown in Figure S1), 7-hydroxy- (S1), 7-methyl(S2) and 7-methoxycoumarin (S3) were inactive, as were styrenyloxy- (S11), naphthylmethyloxy- (S14), isoprenoxy- (S13), and several annulated coumarins and analogues containing an additional fused ring. Based on the initial SAR, compounds having different C7 substitutions were synthesized, as well as compounds with acetic acid replacements.

\section{Synthesis.}

Scheme 1 shows the synthesis of $\mathbf{4 a a - 4 b j}$. Pechmann reaction of 2-methyl resorcinol with dimethyl acetylsuccinate in the presence of sulfuric acid afforded 4,8-dimethyl-7hydroxycoumarin ester $\mathbf{2}$ in $86 \%$ yield. O-alkylation of 2 with alkyl bromides (3aa-3aj) or aryl methylbromides (3ak-3ap, 3at-3bj) gave substituted benzyloxy-4,8dimethylcoumarins 3aa-3bj in 28-98\% yields, which were hydrolyzed with $1 \mathrm{~N}$ sodium hydroxide in methanol to give $\mathbf{4 a a - 4 b j}$ in $\mathbf{5 2 - 9 6 \% ~ y i e l d s . ~ F o r ~ t h e ~ b e n z e n e s u l f o n y l ~}$ analogues 3aq and 3ar, substitution of 2 with $m$-Cl-, or $m-\mathrm{CH}_{3}$-benzenesulfonyl chloride with potassium carbonate give 3aq and 3ar in 68 and 71\% yields, respectively. Hydrolysis of esters 3aq and 3ar was accomplished with lithium hydroxide in acetonitrile to afford 4aq and 4ar.

Scheme 2 shows the synthesis of formic acid derivatives 8aa-8ad. Methyl 8-methyl-7hydroxybenzopyranone-3-carboxyl-ate $\mathbf{6 a}$ was prepared by condensation of 2,4dihydroxy-3-methylbenzaldehyde 5 with dimethyl malonate under sulfuric acid conditions. Alkylation of $\mathbf{6} \mathbf{a}$ with substituted benzyl bromide afforded $7 \mathbf{a a}$ and $\mathbf{7} \mathbf{a b}$, which were hydrolyzed to give 8aa and 8ab. Aminolysis of 7aa with ammonia gas in tetrahydrofuran (THF) gave amide analogue 8ac. Hydroxamic acid analogue 8ad was synthesized by reaction of ester 7aa with hydroxylamine under basic conditions. For the propionic acid analogues, Pechmann type reaction with 2-methyl resorcinol and diethylacetyl glutarate under acidic conditions afforded $\mathbf{6 b}$. O-alkylation of $\mathbf{6 b}$ with bromo- or iodobenzyl bromide gave 7ba-7bb which upon hydrolysis under basic conditions gave $\mathbf{8 b a - 8 b b}$. 


\section{SAR Analysis for Inhibition of slc26a3-Mediated Chloride/lodide Exchange.}

All synthesized analogues were tested for inhibition of slc26a3-mediated chloride/iodide exchange using a cell-based kinetic assay in which fluorescence was measured in Fischer rat thyroid cells expressing (murine) slc26a 3 and a yellow fluorescent protein halide sensor (YFP) following extracellular addition of iodide. ${ }^{12}$ Table 1 summarizes slc26a3 inhibition data for compounds with different $\mathrm{C} 7$ substituents.

Slc26a3 inhibition was compared for analogues containing various alkyl, allyl, heterocyclic, benzenesulfonyl, and substituted benzyl groups at C7. Propyl (4ad) or allyl (4aa) analogues showed no inhibition at $5 \mu \mathrm{M}$. Inhibition with micromolar $\mathrm{IC}_{50}$ was seen with elongated alkyl chains, including butoxy-, pentoxy-, and hexyloxy-analogues (4ae-4ag). Analogues containing cyclic alkyl chains (4ah-4aj) showed mildly reduced inhibition compared to linear alkyl analogues (4ad-4ag). To investigate heterocyclic analogues, substituted pyridines, pyrrol, and 5-trifluoromethylfuran were studied. Pyridine (4ak-4an) and pyrrol (4ap) analogues were inactive at $5 \mu \mathrm{M}$, with only the 5-trifluoromethylfuran analogue (4ao) showing strong activity with $\mathrm{IC}_{50}$ of $0.3 \mu \mathrm{M}$, similar to that of original compound $\mathrm{DRA}_{\text {inh }^{-}}$ A250 (4ba). To investigate benzyl analogues, $o$-, $m$ - and $p$-halobenzyl bromides were studied (4at-4bc). $p$-Substituted halobenzyl analogues (4at-4av) showed no inhibition at 5 $\mu \mathrm{M}$, whereas $o$-substituted halobenzyl analogues (4aw-4ay) showed weak inhibition, with $\mathrm{IC}_{50}$ of $4.5 \mu \mathrm{M}$ for $o$-iodobenzyl (4aw), $10 \mu \mathrm{M}$ for $o$-bromobenzyl (4ax), and $18 \mu \mathrm{M}$ for $o-$ chlorobenzyl (4ay) analogues.

Notably, m-substituted halobenzyl analogues showed strong inhibition, with $\mathrm{IC}_{50}$ of 0.04 $\mu \mathrm{M}$ for iodobenzyl 4az. With the knowledge that meta-substitution increased inhibition activity, we studied $m$-nitro $4 \mathbf{b d}, m$-trifluoromethyl $4 \mathbf{b e}$, and $m$-cyclopropyl $4 \mathbf{b f}$ analogues. $m$-Nitrobenzyl $\mathbf{4 b d}$ was less potent $\left(\mathrm{IC}_{50} 0.5 \mu \mathrm{M}\right)$ than $\mathbf{4 b b}$, and $m$-cyclopropylbenzyl $\mathbf{4 b f}$ was more potent $(0.07 \mu \mathrm{M})$, with $m$-trifluoromethylbenzyl 4 be having the greatest potency with $\mathrm{IC}_{50}$ of $0.025 \mu \mathrm{M}$. For comparison, the commercially available $m$-methylbenzyl analogue $4 \mathbf{b k}$ had $\mathrm{IC}_{50}$ of $0.5 \mu \mathrm{M}$. The 3,5-dimethylbenzyl analogue $4 \mathbf{b g}$ had much reduced potency compared to its mono-substituted analogue $4 \mathbf{b k}$, and 3,5-bistrifluoromethylbenzyl analogue $\mathbf{4 b h}\left(\mathrm{IC}_{50} 0.3 \mu \mathrm{M}\right)$ was much less potent than monosubstituted $\mathbf{4 a z}$.

Additional F-substitutions (4bi, $\mathbf{4 b j}$ ) containing $m$-trifluoromethylbenzyl mildly reduced inhibition compared to $\mathbf{4 a z}$, with additional $m$-substitution (4bj) showing greater inhibition than $o$-substitution (4bi). $m$-Trifluoromethylphenethyl analogue 4as showed no inhibition at $5 \mu \mathrm{M}$. Benzenesulfonyl analogues $\mathbf{4 a q}$ and 4 ar showed no inhibition at $5 \mu \mathrm{M}$.

Next, the acetic acid portion on $\mathrm{C} 3$ was investigated. Preliminary data showed that acetic acid had much greater inhibition potency than its corresponding ester, and that benzyl or alkyl in place of acetic acid reduced inhibition. To determine the best acid substituents on $\mathrm{C} 3$, we tested formic acid and propionic acid analogues with Br- or I-substituted 7oxybenzyl-8-dimethylcoumarin. As listed in Table 2, replacement of acetic acid on C3 with formic acid (8aa-8ab) or propionic acid (8ba-8bb) reduced inhibition. Interestingly, hydroxamic acid 8ad had $\mathrm{IC}_{50}$ of $0.45 \mu \mathrm{M}$, whereas its corresponding acid 8aa was inactive. To compare with $\mathbf{4 b a}$, the corresponding amide of $\mathbf{8 a a}$, namely $\mathbf{8 a e}$, showed much reduced 
inhibition, supporting the importance of the acetic acid moiety for inhibition. To investigate inhibitor selectivity, $\mathbf{4 b e}$ and $\mathbf{4 a z}$ were chosen for further studies.

Inhibition of DRA (slc26a3)-Mediated Chloride/Bicarbonate Exchange.

The concentration-dependence measurements reported in Tables 1 and 2 were done for inhibition of slc26a3-mediated chloride/iodide exchange. Figure 1A shows representative data obtained using the YFP quenching assay, which fitted well to a single-site inhibition model with $\mathrm{IC}_{50}$ of 0.040 and $0.025 \mu \mathrm{M}$ for $\mathbf{4 a z}$ and $\mathbf{4 b e}$, respectively. For chloride/ bicarbonate exchange, which is the physiologically relevant transport process in colon, cytoplasmic $\mathrm{pH}$ was measured in slc26a3-expressing Fischer rat thyroid epithelial cells (FRT) cells using the $\mathrm{pH}$-sensitive fluorescent indicator $2^{\prime}, 7^{\prime}$-bis(carboxy ethyl)-5(6)carboxyfluorescein (BCECF). ${ }^{15}$ BCECF-labeled cells were incubated with a chloride- and bicarbonate-containing solution, after which a chloride-free, bicarbonate-containing solution was added. The rate of cytoplasmic alkalinization was inhibited by $\mathbf{4 a z}$ and $\mathbf{4 b e}$ with $\mathrm{IC}_{50}$ values of 0.035 and $0.023 \mu \mathrm{M}$, respectively (Figure 1B). In control experiments, no change in cytoplasmic $\mathrm{pH}$ was observed in cells not expressing slc26a3, or in experiments where bicarbonate was replaced with chloride in exchange solutions (not shown).

\section{DRA Inhibition Selectivity of $4 \mathrm{az}$ and $4 \mathrm{bee}$}

To study selectivity, anion exchange assays were done on related solute carrier 26 family members, including (murine) slc26a4 (pendrin; 48\% amino acid identity to slc26a3), (murine) slc26a6 (PAT-1; 38\% amino acid identity), and (human) SLC26A9 ( 39\% amino acid identity). Chloride/iodide exchange was not significantly inhibited by $10 \mu \mathrm{M} 4 \mathbf{a z}$ or $4 \mathbf{b e}$ in cells expressing each of these solute carrier family 26 members, with original fluorescence time course data shown in Figure 2A and summary data in Figure 2B. Based on the inhibition activity, aqueous solubility and preliminary in vitro microsomal stability experiments (data not shown), $\mathbf{4 b e}$ and $\mathbf{4 a z}$ were chosen for further studies including in vivo efficacy.

\section{Pharmacokinetics in Mice.}

Figure 3 shows the serum concentrations of $\mathbf{4 b a}, \mathbf{4 b e}$, and $4 \mathbf{a z}$ after single dose $(5 \mathrm{mg} / \mathrm{kg}$ for 4ba and $4 \mathbf{b e}, 10 \mathrm{mg} / \mathrm{kg}$ for $\mathbf{4 a z}$ ) oral or intraperitoneal administration at zero time. 4 ba had levels well above the $\mathrm{IC}_{50}$ determined in vitro for at least $24 \mathrm{~h}$ after single dose oral or intraperitoneal administration. 4be had high serum levels initially, but disappeared relatively rapidly with little compound remaining at $16 \mathrm{~h}$. $4 \mathrm{az}$ had predicted therapeutic concentrations for several days after single dose oral or intraperitoneal administration, with serum concentration of $\mathbf{4 a z}$ of approximately $1 \mu \mathrm{M}$ even at $72 \mathrm{~h}$. The deduced pharmacokinetic parameters for $\mathbf{4 b a}, \mathbf{4 b e}$, and $\mathbf{4 a z}$ are given in Table 3. Computed oral bioavailability values were (mean \pm S.E.M.): $54 \pm 6.5 \%$ (4ba), $16 \pm 7 \%$ (4be) and $39 \pm 4 \%$ (4az).

\section{Efficacy in a Mouse Model of Constipation.}

Opioids such as loperamide slow gut motility ${ }^{13}$ and are commonly used to induce constipation in animal models as they have direct relevance to opioid-induced constipation, one of the most common types of constipation. Figure 4A shows the experimental model in 
which the slc26a3 inhibitor was administered orally $1 \mathrm{~h}$ prior to intraperitoneal injection of loperamide, with stool collected over the following $3 \mathrm{~h}$. As shown in Figure 4B, 4be administration partially prevented constipation in loperamide-treated mice as quantified by improved $3 \mathrm{~h}$ stool weight, pellet number, and water content. The efficacy of $\mathbf{4 b e}$ was similar to that found previously for original inhibitor $\mathbf{4 b a} .{ }^{12}$ Notably, $\mathbf{4 a z}$ administration fully normalized stool water content in loperamide-treated mice (Figure 4C), even at a low dose of $3 \mathrm{mg} / \mathrm{kg}$. In control mice not treated with loperamide, $4 \mathbf{a z}$ had no significant effect on stool parameters compared to vehicle treatment.

\section{DISCUSSION AND CONCLUSION}

The goal of this study was to advance 4,8-dimethylcoumarin inhibitors of the slc26a3 anion exchange protein for anti-absorptive therapy of constipation. SAR analysis of commercially available 4,8-dimethylcoumarin analogues as well as a focused library of synthesized compounds identified compounds with $\sim 10$-fold improved potency compared with reference compound 4ba, with good pharmacokinetic properties and efficacy in a mouse model of constipation when administered orally. A low oral dose $(1 \mathrm{mg} / \mathrm{kg})$ of $\mathbf{4 a z}$ produced greater than 50\% normalization of stool hydration in loperamide-treated mice, suggesting effective compound accumulation in enterocytes in colon. It is not possible, however, to directly relate serum concentrations to efficacy in constipation because we do not know the concentration of free compound in serum, the intracellular compound concentration, and whether the compound accumulates in enterocytes by delivery from the luminal or basolateral surfaces of the colonic epithelium. We speculate, though do not know with certainty, that the 4,8dimethylcoumarins act from the cytoplasmic surface of slc26a3 because they were effective when administered intraperitoneally (data not shown) and their onset of action was not immediate in cell cultures in vitro. ${ }^{12}$ Depending on their physicochemical properties, slc26a3 inhibitors could accumulate at their target site, the colonic epithelium, by delivery from the luminal membrane with minimal systemic absorption, or by absorption in small intestine and delivery from the basolateral membrane.

Compounds $4 \mathbf{b e}, \mathbf{4 a z}$, and $\mathbf{4 b a}$ have favorable drug-like properties according to the Lipinski's rule of $5,{ }^{14}$ with molecular mass less than $500 \mathrm{Da}(406,464$, and 416, respectively), tPSA of 72.8, $\mathrm{p} K_{\mathrm{a}}$ of 3.70, clog $P$ of 4.6-4.8, and multiple hydrogen bond acceptors and donors. In general, coumarins are polyphenolic derivatives found in plants that contain a benzopyranone moiety. They are considered as phytoalexins with diverse cytoprotective and modulatory activities including antimicrobial, antiviral, anticancer, antiinflammatory, antioxidant, and central nervous system activities. ${ }^{16}$ Prior studies have provided information on the coumarin substituents $(\mathrm{C} 3,4,7$, and 8) involved in the various biological activities. For example, 3 -acetic acid coumarin analogues have methicillinresistance Staphylococcus aureus antibacterial activity, ${ }^{17}$ DNA gyrase inhibition, ${ }^{18}$ ATPase inhibition, ${ }^{19}$ antituberculosis activity, ${ }^{20}$ and inhibition of nuclear factor kappa-light-chainenhancer of activated B cells (NF- $x$ B)/DNA interaction. ${ }^{21} 3$-Carboxamide coumarin analogues inhibit monoamine oxidase. ${ }^{22,23}$ The most widely used coumarin-containing drug is warfarin. ${ }^{24}$ Warfarin and its analogues contain a hydroxyl group at C4, in which its replacement by sulfhydryl, halogen, or hydrogen abolished anticoagulant activity. ${ }^{25}$ The compounds reported herein are not expected to have anticoagulant activity because they do 
not contain a 4-hydroxy group. For the $\mathrm{C} 7$ substituent on coumarin, 6,7-annulated coumarins were reported as inhibitors of NF- $\kappa \mathrm{B} / \mathrm{DNA}$ interaction, ${ }^{26,27}$ and $\mathrm{C} 7$ biaryl coumarin analogues as antibacterials. ${ }^{28}$

This study builds on our original identification, by high-throughput screening, of the first selective inhibitors of anion exchanger SLC26A3. ${ }^{12}$ Compounds 4 be and $4 \mathbf{a z}$ synthesized and characterized herein fully inhibited slc26a3-mediated anion exchange with $\mathrm{IC}_{50}$ down to $25 \mathrm{nM}$. 4az gave sustained therapeutic concentration in serum for over $72 \mathrm{~h}$ after singledose oral or intraperitoneal administration and fully normalized stool hydration in a loperamide mouse model of constipation. Having favorable inhibition potency in vitro and in vivo, selectivity within the SLC26 family, and pharmacokinetics, $4 \mathbf{a z}$ is suitable candidate for further preclinical development.

\section{EXPERIMENTAL DETAILS}

\section{General Synthesis Procedure.}

All chemicals and solvents were used as purchased and used without further purification. Reaction progress was monitored by thin-layer chromatography using pre-coated silica gel plates with fluorescence at $254 \mathrm{~nm}$ and ethylacetate/ $n$-hexane solvent system. ${ }^{1} \mathrm{H}$ and ${ }^{13} \mathrm{C}$ NMR spectra were obtained on a Bruker AVANCE 300 instrument using $\mathrm{CDCl}_{3}, \mathrm{CD}_{3} \mathrm{OD}$, trifluoroacetic acid- $d$, acetic acid- $d_{4}$, or dimethyl sulfoxide (DMSO)- $d_{6}$ as solvent. Chemical shifts are given in parts per million (ppm). HRMS was performed using a hybrid quadrupole Orbitrap mass analyzer, Q Exactive (Thermo, Bremen, Germany) with an electrospray ionization source. The mass resolution was set as 70000 at $\mathrm{m} / \mathrm{z} 200$, and mass accuracy $>3$ ppm. Purity of all final compounds was $95 \%$ or higher as determined by high performance liquid chromatography (HPLC) using UV absorbance at $254 \mathrm{~nm}$. HPLC was done on an XTerra MS C18 column $(2.1 \mathrm{~mm} \times 100 \mathrm{~mm}, 3.5 \mu \mathrm{m})$ with $0.2 \mathrm{~mL} / \mathrm{min}$ water/acetonitrile (containing $0.1 \%$ formic acid), 25 min linear gradient, 5-95\% acetonitrile.

\section{Methyl 2-(7-Hydroxy-4,8-dimethyl-2-oxo-2H-chromen-3-yl) Acetate (2).}

To a solution of 2-methylresorcinol $(5.0 \mathrm{~g}, 40 \mathrm{mmol})$ and dimethyl 2-acetylsuccinate $(7.6 \mathrm{~g}$, $40 \mathrm{mmol})$ in absolute methanol $(40 \mathrm{~mL})$ was added $20 \mathrm{~mL}$ of sulfuric acid at $0{ }^{\circ} \mathrm{C}$ for $1 \mathrm{~h}$.

The reaction mixture was stirred at room temperature for $24 \mathrm{~h}$ and then the mixture was poured into water. The resulting precipitate was collected by filtration, washed with water, and dried at $50{ }^{\circ} \mathrm{C}$ under vacuum overnight to give an off-white solid $(9.0 \mathrm{~g}, 86 \%$ yield) of the desired product. ${ }^{1} \mathrm{H}$ NMR (300 MHz, $\mathrm{CDCl}_{3}$ ): $\delta 7.14(\mathrm{~d}, 1 \mathrm{H}, J=8.2 \mathrm{~Hz}), 6.65(\mathrm{~d}, 1 \mathrm{H}, J$ $=8.2 \mathrm{~Hz}), 3.81(\mathrm{~s}, 3 \mathrm{H}), 3.74(\mathrm{~s}, 2 \mathrm{H}), 2.32(\mathrm{~s}, 3 \mathrm{H}), 2.21(\mathrm{~s}, 3 \mathrm{H}) ;{ }^{13} \mathrm{C} \mathrm{NMR}\left(75 \mathrm{MHz}, \mathrm{CDCl}_{3}\right)$ : $\delta 172.7,162.3,157.3,151.7,150.1,122.5,114.9,113.1,111.8,111.5,52.6,32.7,15.3,7.9$; LRMS: $263\left(\mathrm{M}+\mathrm{H}^{+}\right)$.

\section{Methyl 2-(7-((3-Bromobenzyl)oxy)-4,8-dimethyl-2-oxo-2H-chromen-3-yl)acetate (3ba).}

A mixture of 2 (200 mg, $0.8 \mathrm{mmol})$, bromobenzyl bromide ( $270 \mathrm{mg}, 1.1 \mathrm{mmol})$, and potassium carbonate $(210 \mathrm{mg}, 1.5 \mathrm{mmol})$ in acetone $(10 \mathrm{~mL})$ was heated at reflux overnight. The reaction mixture was cooled to $\mathrm{rt}$ and poured into ice water. The resulting precipitate was collected by filtration, washed with methanol, and dried to give $170 \mathrm{mg}(96 \%)$ of the 
product as white solid. ${ }^{1} \mathrm{H}$ NMR $\left(300 \mathrm{MHz}, \mathrm{CDCl}_{3}\right): \delta 7.61(\mathrm{br} \mathrm{s}, 1 \mathrm{H}), 7.51-7.48(\mathrm{~m}, 1 \mathrm{H})$, $7.46(\mathrm{~d}, 1 \mathrm{H}, J=8.9 \mathrm{~Hz}), 7.39(\mathrm{~d}, 1 \mathrm{H}, J=8.0 \mathrm{~Hz}), 7.29(\mathrm{t}, 1 \mathrm{H}, J=7.8 \mathrm{~Hz}), 6.87(\mathrm{~d}, 1 \mathrm{H}, J=$ $8.9 \mathrm{~Hz}$ ), 3.75 (br s, 2H), 3.73 (s, 3H), 2.39 (br s, $6 \mathrm{H}$ ); ${ }^{13} \mathrm{C} \mathrm{NMR}\left(75 \mathrm{MHz}, \mathrm{CDCl}_{3}\right.$ ): $\delta 170.9$, 161.8, 158.6, 151.6, 149.0, 138.8, 131.2, 130.2, 130.0, 125.5, 122.76, 122.72, 116.5, 114.5, 114.4, 108.1, 69.5, 52.2, 32.7, 15.3, 8.4; LRMS: $431\left(\mathrm{M}+\mathrm{H}^{+}\right)$.

\section{2-(7-((3-Bromobenzyl)oxy)-4,8-dimethyl-2-oxo-2H-chromen-3-yl)acetic Acid (4ba).}

To a solution of methyl ester $3 \mathbf{b a}(160 \mathrm{mg}, 0.4 \mathrm{mmol})$ in methanol $(8 \mathrm{~mL})$ was added $\mathrm{NaOH}$ $(25 \mathrm{mg}, 0.6 \mathrm{mmol})$ in water $(2 \mathrm{~mL})$ and refluxed for $1 \mathrm{~h}$. The mixture was cooled to room temperature, diluted with water, and acidified with $1 \mathrm{~N} \mathrm{HCl}$. The resulting precipitate was collected by filtration, washed with water, and dried. The final product was recrystallized in methanol to give the product as a white powder $(105 \mathrm{mg}, 68 \%) .{ }^{1} \mathrm{H} \mathrm{NMR}(300 \mathrm{MHz}$, DMSO- $\left.d_{6}\right): \delta 7.70(\mathrm{br} \mathrm{s}, 1 \mathrm{H}), 7.65(\mathrm{~d}, 1 \mathrm{H}, J=9.0 \mathrm{~Hz}), 7.55(\mathrm{~d}, 1 \mathrm{H}, J=8.4 \mathrm{~Hz}), 7.51(\mathrm{~d}, 1 \mathrm{H}$, $J=7.9 \mathrm{~Hz}), 7.41(\mathrm{~d}, 1 \mathrm{H}, J=7.9 \mathrm{~Hz}), 7.12(\mathrm{~d}, 1 \mathrm{H}, J=9.0 \mathrm{~Hz}), 5.29(\mathrm{~s}, 2 \mathrm{H}), 3.51(\mathrm{~s}, 2 \mathrm{H})$, $2.34(\mathrm{~s}, 3 \mathrm{H}), 2.26(\mathrm{~s}, 3 \mathrm{H}) ;{ }^{13} \mathrm{C}$ NMR (75 MHz, DMSO- $\left.d_{6}\right): \delta 172.0,161.4,158.4,151.1$, 149.1, 140.1, 131.2, 130.4, 126.7, 124.0, 122.2, 117.8, 114.4, 112.9, 109.2, 69.3, 52.2, 15.5, 8.5; HRMS for $\mathrm{C}_{20} \mathrm{H}_{17} \mathrm{BrO}_{5}$ : calcd, 417.0332; found, $417.0330\left(\mathrm{M}+\mathrm{H}^{+}\right)$.

Mice.

Mice were bred at the University of California San Francisco (UCSF) animal facility. Animal protocols were approved by the UCSF Institutional Animal Care and Use Committee.

\section{Pharmacokinetics.}

Pharmacokinetics of $\mathbf{4 b a}, \mathbf{4 b e}$ and $\mathbf{4 a z}$ were determined in mice. Following single-dose intraperitoneal or oral administration of $4 \mathbf{b a ~}(5 \mathrm{mg} / \mathrm{kg}$, in saline with 5\% DMSO and $10 \%$ Kolliphor HS 15), 4 be $(5 \mathrm{mg} / \mathrm{kg}$, same vehicle as $4 \mathbf{b a})$ or $4 \mathbf{a z}(10 \mathrm{mg} / \mathrm{kg}$, in phosphate buffered saline (PBS) with 5\% DMSO and 20\% 2-hydroxypropyl- $\beta$-cyclodextrin), blood samples were collected via retroorbital puncture at specified time points and serum was separated by centrifugation at $4000 \mathrm{~g}$ for $20 \mathrm{~min}$ at $24^{\circ} \mathrm{C}$. Compound concentrations were measured in serum using liquid chromatography (LC)/mass spectrometry (MS). Oral bioavailability was calculated by using area under the curve (AUC) for oral and ip routes as AUC (oral)/AUC (ip).

\section{Loperamide Constipation Model.}

Female CD1 mice (age 8-10 weeks) were administered loperamide $(0.3 \mathrm{mg} / \mathrm{kg}$, intraperitoneally, in $5 \%$ ethanol in PBS, $0.1 \mathrm{mg} / \mathrm{mL}$ final concentration) to produce constipation or vehicle in control mice. 4 be $(5 \mathrm{mg} / \mathrm{kg}), 4 \mathbf{a z}(1,3$ or $10 \mathrm{mg} / \mathrm{kg}$, in PBS with $5 \%$ DMSO and 20\% 2-hydroxypropyl- $\beta$-cyclodextrin) or vehicle were administered by oral gavage $1 \mathrm{~h}$ before loperamide. After loperamide injection, mice were placed individually in metabolic cages with free access to food and water. Stool samples were collected for $3 \mathrm{~h}$, and total stool weight and number of fecal pellets were quantified. To measure stool water content, stool samples were dried at $80{ }^{\circ} \mathrm{C}$ for $24 \mathrm{~h}$ and water content was calculated as [wet weight - dry weight $] /$ wet weight. ${ }^{5,6}$ 


\section{Anion Exchange Assays.}

Assay of (murine) slc26a3-mediated chloride/iodide exchange was done as described ${ }^{12}$ in which FRT rat thyroid epithelial cells expressing slc26a3 and halide-sensitive EYFPH148Q/ I152L/F46L were incubated in PBS prior to addition of iodide-substituted PBS (140 mM $\mathrm{NaCl}$ substituted with $\mathrm{NaI}$ ). The rate of fluorescence quenching was determined as a quantitative measure of chloride/iodide exchange. Measurement of chloride/bicarbonate exchange was done as described ${ }^{15}$ in which intracellular $\mathrm{pH}$ in FRT cells expressing slc26a3 was measured using the $\mathrm{pH}$-sensitive probe BCECF in a bicarbonate-containing buffer following chloride replacement by gluconate. Transporter selectivity was studied as described $^{12}$ in which FRT cells containing slc26a transporters were preincubated with 0 or $10 \mu \mathrm{M} 4 \mathbf{a z}$ or $4 \mathbf{b e}$ for $10 \mathrm{~min}$ prior to anion exchange assay.

\section{Supplementary Material}

Refer to Web version on PubMed Central for supplementary material.

\section{ACKNOWLEDGMENTS}

The authors thank Joseph-Anthony Tan for assistance with transport assays and Amber A. Rivera for assistance with cell culture. The authors thank to Dr. Robert Yen of the SFSU Mass Spectrometry Facility for HRMS measurements, funded by National Science foundation grant CHE-1228656.

Funding

This work was supported by grants from the NIH (DK72517, DK099803, DK 101373), Cystic Fibrosis Foundation (VERKMA18G0), University of California Drug Discovery Consortium and the UCSF Clinical \& Translational Science Institute Catalyst Program.

\section{ABBREVIATIONS}

DRA

SAR

AUC

ip interperitoneal

po

slc26a3

YFP

BCECF

FRT

per oral

\section{down-regulated in adenoma}

structure-activity relationship

area under the curve

solute carrier 26 family member a3

yellow fluorescent protein halide sensor

$2^{\prime}, 7^{\prime}$-bis(carboxy ethyl)-5(6)-carboxyfluorescein

Fischer rat thyroid epithelial cells

\section{REFERENCES}

(1). Rao SSC; Rattanakovit K; Patcharatrakul T Diagnosis and Management of Chronic Constipation in Adults. Nat. Rev. Gastroenterol. Hepatol 2016, 13, 295-305. [PubMed: 27033126] 
(2). Sabharwal S Gastrointestinal Manifestations of Cystic Fibrosis. Gastroenterol. Hepatol 2016, 12, 43-47.

(3). Camilleri M; Ford AC; Mawe GM; Dinning PG; Rao SS; Chey WD; Simrén M; Lembo A; YoungFadok TM; Chang L Chronic Constipation. Nat. Rev. Dis. Primers 2017, 3, 17096.

(4). Bharucha AE; Wouters MM; Tack J Existing and Emerging Therapies for Managing Constipation and Diarrhea. Curr. Opin. Pharmacol 2017, 37, 158-166. [PubMed: 29172123]

(5). Cil O; Phuan P-W; Lee S; Tan J; Haggie PM; Levin MH; Sun L; Thiagarajah JR; Ma T; Verkman AS CFTR Activator increases Intestinal Fluid Secretion and Normalizes Stool Output in a Mouse Model of Constipation. Cell. Mol. Gastroenterol. Hepatol 2016, 2, 317-327. [PubMed: 27127798]

(6). Cil O; Phuan P-W; Son J-H; Zhu JS; Ku CK; Tabib NA; Teuthorn AP; Ferrera L; Zachos NC; Lin R; Galietta LJV; Donowitz M; Kurth MJ; Verkman AS Phenylquinoxalinone CFTR activator as Potential Prosecretory Therapy for Constipation. Transl. Res 2017, 182, 14-26. [PubMed: 27815136]

(7). Talbot C; Lytle C Segregation of Na/H Exchanger-3 and Cl/HCO3 Exchanger SLC26A3 (DRA) in Rodent Cecum and Colon. Am. J. Physiol. Gastrointest. Liver Physiol 2010, 299, G358-G367. [PubMed: 20466943]

(8). Byeon MK; Westerman MA; Maroulakou IG; Henderson KW; Suster S; Zhang XK; Papas TS; Vessely J; Willingham MC; Green JE; Schweinfest CW The Down-Regulated in Adenoma (DRA) Gene Encodes an Intestine-Specific Membrane Glycoprotein. Oncogene 1996, 12, 387 396. [PubMed: 8570216]

(9). Walker NM; Simpson JE; Yen PF; Gill RK; Rigsby EV; Brazill JM; Dudeja PK; Schweinfest CW; Clarke LL Down-Regulated in Adenoma Cl/HCO3 Exchanger Couples with Na/H Exchanger 3 for $\mathrm{NaCl}$ Absorption in Murine Small Intestine. Gastroenterology 2008, 135, 1645-1653. [PubMed: 18930060]

(10). Höglund P; Haila S; Socha J; Tomaszewski L; Saarialho-Kere U; Karjalainen-Lindsberg M-L; Airola K; Holmberg C; de la Chapelle A; Kere J Mutations of the Down-Regulated in Adenoma (DRA) Gene cause Congenital Chloride Diarrhoea. Nat. Genet 1996, 14, 316-319. [PubMed: 8896562]

(11). Schweinfest CW; Spyropoulos DD; Henderson KW; Kim J-H; Chapman JM; Barone S; Worrell RT; Wang Z; Soleimani M Slc26a3 (DRA)-Deficient Mice Display Chloride-losing Diarrhea, Enhanced Colonic Proliferation, and Distinct Up-Regulation of Ion Transporters in the Colon. J. Biol. Chem 2006, 281, 37962-37971. [PubMed: 17001077]

(12). Haggie PM; Cil O; Lee S; Tan J-A; Rivera AA; Phuan P-W; Verkman AS SLC26A3 Inhibitor Identified in Small Molecule Screen Blocks Colonic Fluid Absorption and Reduces Constipation. JCI Insight 2018, 3, No. e121370.

(13). Galligan JJ; Sternini C Insights into the Role of Opioid Receptors in the GI Tract: Experimental Evidence and Therapeutic Relevance. Handb. Exp. Pharmacol 2017, 239, 363-378. [PubMed: 28204957]

(14). Lipinski CA; Lombardo F; Dominy BW; Feeney PJ Experimental and Computational Approaches to Estimate Solubility and Permeability in Drug Discovery and Development Settings. Adv. Drug Delivery Rev 2001, 46, 3-26.

(15). Haggie PM; Phuan P-W; Tan J-A; Zlock L; Finkbeiner WE; Verkman AS Inhibitors of Pendrin Anion Exchange Identified in a Small Molecule Screen Increase Airway Surface Liquid Volume in Cystic Fibrosis. FASEB J. 2016, 30, 2187-2197. [PubMed: 26932931]

(16). Kontogiorgis C; Detsi A; Hadjipavlou-Litina D Coumarin-Based Drugs: a Patent Review (2008 present). Expert Opin. Ther. Pat 2012, 22, 437-454. ; and references therein [PubMed: 22475457]

(17). Cheng T-JR; Wu Y-T; Yang S-T; Lo K-H; Chen S-K; Chen Y-H; Huang W-I; Yuan C-H; Guo CW; Huang L-Y; Chen K-T; Shih H-W; Cheng Y-SE; Cheng W-C; Wong C-H High-Throughput Identification of Antibacterials Against Methicillin-Resistant Staphylococcus Aureus (MRSA) and the Transglycosylase. Bioorg. Med. Chem 2010, 18, 8512-8529. [PubMed: 21075637]

(18). Ferroud D; Collard J; Klich M; Dupuis-Hamelin C; Mauvais P; Lassaigne P; Bonnefoy A; Musicki B Synthesis and Biological Evaluation of Coumarincarboxylic Acids as Inhibitors of 
Gyrase B. L-rhamnose as an Effective Substitute for L-noviose. Bioorg. Med. Chem. Lett 1999, 9, 2881-2886. [PubMed: 10522711]

(19). Marzaro G; Lampronti I; Borgatti M; Manzini P; Gambari R; Chilin A Psoralen derivatives as inhibitors of NF- $x$ B/DNA interaction: the critical role of the furan ring. Mol. Diversity 2015,19 , 551-561.

(20). Matano LM; Morris HG; Hesser AR; Martin SES; Lee W; Owens TW; Laney E; Nakaminami H; Hooper D; Meredith TC; Walker S Antibiotic That Inhibits the ATPase Activity of an ATPBinding Cassette Transporter by Binding to a Remote Extracellular Site. J. Am. Chem. Soc 2017, 139, 10597-10600. [PubMed: 28727445]

(21). Keri RS; Sasidhar BS; Nagaraja BM; Santos MA Recent Progress in the Drug Development of Coumarin Derivatives as Potent Antituberculosis Agents. Eur. J. Med. Chem 2015, 100, 257-269. [PubMed: 26112067]

(22). Chimenti F; Secci D; Bolasco A; Chimenti P; Bizzarri B; Granese A; Carradori S; Yáñez M; Orallo F; Ortuso F; Alcaro S Synthesis, Molecular Modeling, and Selective Inhibitory Activity against Human Monoamine Oxidases of 3-Carboxamido-7-Substituted Coumarins. J. Med. Chem 2009, 52, 1935-1942. [PubMed: 19267475]

(23). Mladenović M; Patsilinakos A; Pirolli A; Sabatino M; Ragno R Understanding the Molecular Determinant of Reversible Human Monoamine Oxidase B Inhibitors Containing 2H-Chromen-2One Core: Structure-Based and Ligand-Based Derived Three-Dimensional Quantitative Structure-Activity Relationships Predictive Models. J. Chem. Inf. Model 2017, 57, 787-814. [PubMed: 28291352]

(24). Wittkowsky AK Warfarin and Other Coumarin Derivatives: Pharmacokinetics, Pharmacodynamics, and Drug Interactions. Semin. Thromb. Hemostasis 2003, 03, 221-230.

(25). Gebauer M Synthesis and Structure-Activity Relationships of Novel Warfarin Derivatives. Bioorg. Med. Chem 2007, 15, 2414-2420. [PubMed: 17275317]

(26). Marzaro G; Guiotto A; Borgatti M; Finotti A; Gambari R; Breveglieri G; Chilin A Psoralen Derivatives as Inhibitors of NF- $\kappa$ B/DNA Interaction: Synthesis, Molecular Modeling, 3D-QSAR, and Biological Evaluation. J. Med. Chem 2013, 56, 1830-1842. [PubMed: 23414143]

(27). Borgatti M; Chilin A; Piccagli L; Lampronti I; Bianchi N; Mancini I; Marzaro G; dall'Acqua F; Guiotto A; Gambari R Development of a Novel Furocoumarin Derivative Inhibiting NF- $x$ B Dependent Biological Functions: Design, Synthesis and Biological Effects. Eur. J. Med. Chem 2011, 46, 4870-4877. [PubMed: 21864947]

(28). Li B; Pai R; Di M; Aiello D; Barnes MH; Butler MM; Tashjian TF; Peet NP; Bowlin TL; Moir DT Coumarin-Based Inhibitors of Bacillus Anthracis and Staphylococcus Aureus Replicative DNA Helicase: Chemical Optimization, Biological Evaluation, and Antibacterial Activities. J. Med. Chem 2012, 55, 10896-10908. [PubMed: 23231076] 

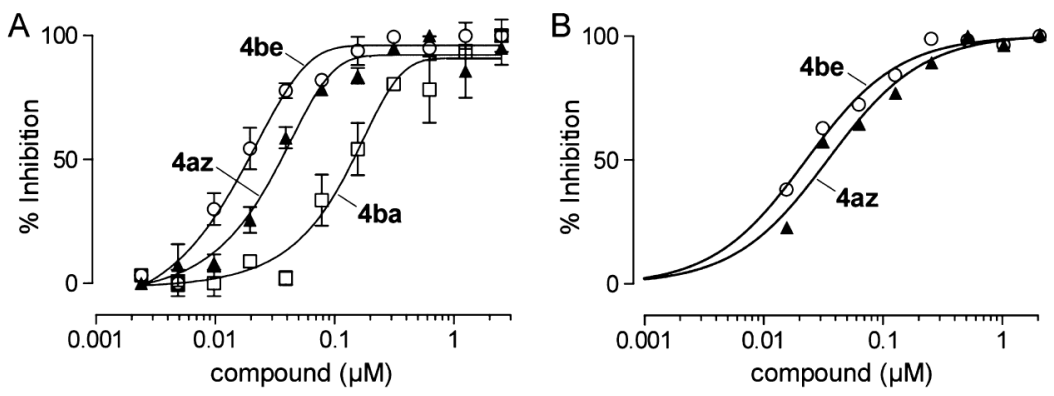

Figure 1.

Concentration-dependent slc26a3-mediated anion exchange inhibition data. (A) Inhibition of slc26a3-mediated $\mathrm{Cl}^{-} / \mathrm{I}^{-}$exchange by indicated compounds (mean \pm S.E.M., $n=3$ ). (B) Inhibition of slc26a3-mediated $\mathrm{Cl}^{-} / \mathrm{HCO}_{3}{ }^{-}$exchange (mean \pm S.E.M., $n=12-28$ individual cell regions analyzed from 3 or more separate replicates). Curves are data fits to the singlesite inhibition model. 

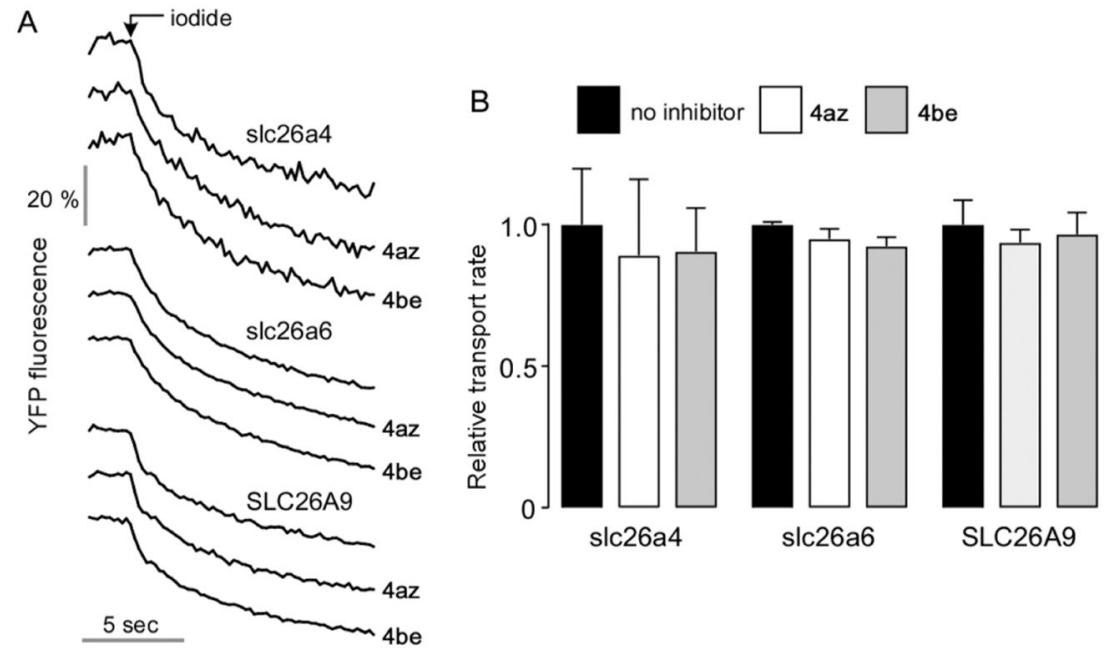

Figure 2.

Selectivity of slc26a3 inhibitors. Original data curves (A) and summary (B) of relative inhibition of slc26a3 analogs by $\mathbf{4 a z}$ and 4 be (mean \pm S.E.M., $n=3$ ). Differences not significant. 

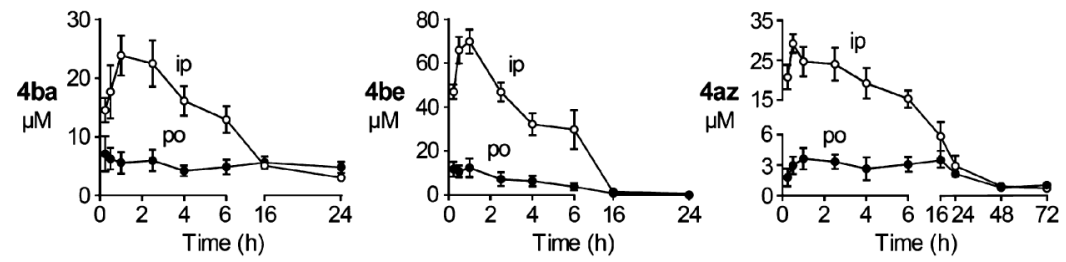

Figure 3.

Pharmacokinetics. Serum concentrations of $\mathbf{4 b a}, \mathbf{4 b e}$, and $\mathbf{4 a z}$ in mice after single dose intraperitoneal or oral administration at $5 \mathrm{mg} / \mathrm{kg}$ (4ba and $4 \mathbf{b e}$ ) or $10 \mathrm{mg} / \mathrm{kg}$ (4az). Mean \pm S.E.M., 3 mice per group. ip: intraperitoneal, po: per oral. 
A

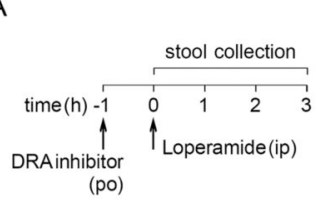

B

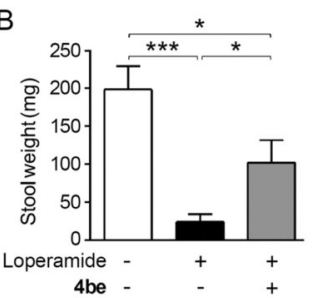

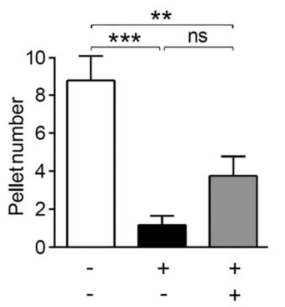
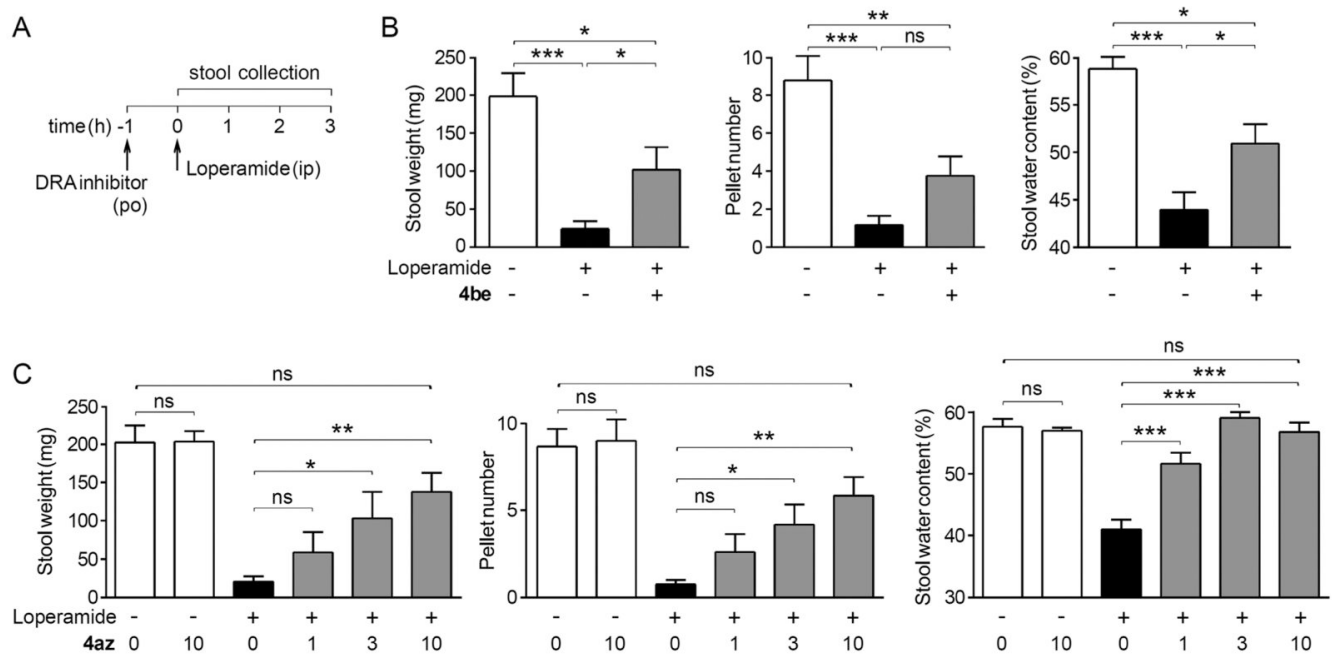

Figure 4.

Inhibitor efficacy in a loperamide-induced constipation model in mice. (A) Experimental protocol. (B) 4 be at $5 \mathrm{mg} / \mathrm{kg}$ improved $3 \mathrm{~h}$ stool weight, pellet number, and water content in loperamide-treated mice (mean \pm S.E.M., 4-6 mice per group). (C) Dose-dependence of 4az (in $\mathrm{mg} / \mathrm{kg}$ ) effect on $3 \mathrm{~h}$ stool weight, pellet number, and water content in loperamide-treated mice (5-8 mice per group, comparisons made with one-way analysis of variance with post hoc Newman-Keuls multiple comparisons test, $* p<0.05, * * p<0.01, * * * p<0.001$, ns: not significant, $\mathrm{p}$ 20.05). ip: intraperitoneal, po: per oral. 


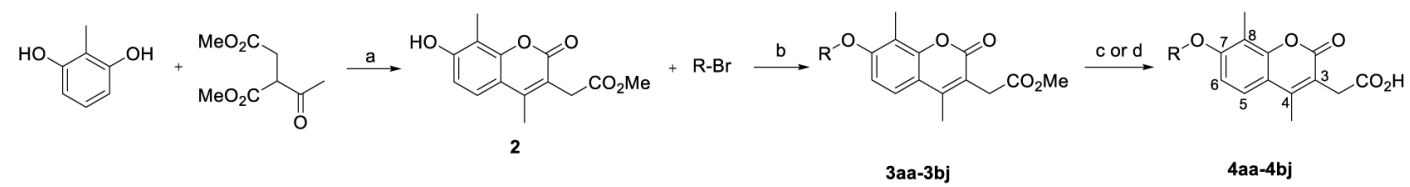

Scheme 1. Synthesis of 4,8-Dimethylcoumarin Analogues ${ }^{a}$

${ }^{a}$ Reagents: (a) $\mathrm{H}_{2} \mathrm{SO}_{4}, \mathrm{MeOH}, 86 \%$. (b) $\mathrm{K}_{2} \mathrm{CO}_{3}$, acetone, reflux, 62-99\%. (c) $\mathrm{NaOH}$, $\mathrm{MeOH}, 75{ }^{\circ} \mathrm{C}, 19-96 \%$. (d) $\mathrm{LiOH}, \mathrm{MeCN}, \mathrm{rt}, 28 \%$ for $\mathbf{4 a q}, 27 \%$ for $\mathbf{4 a r}$. 

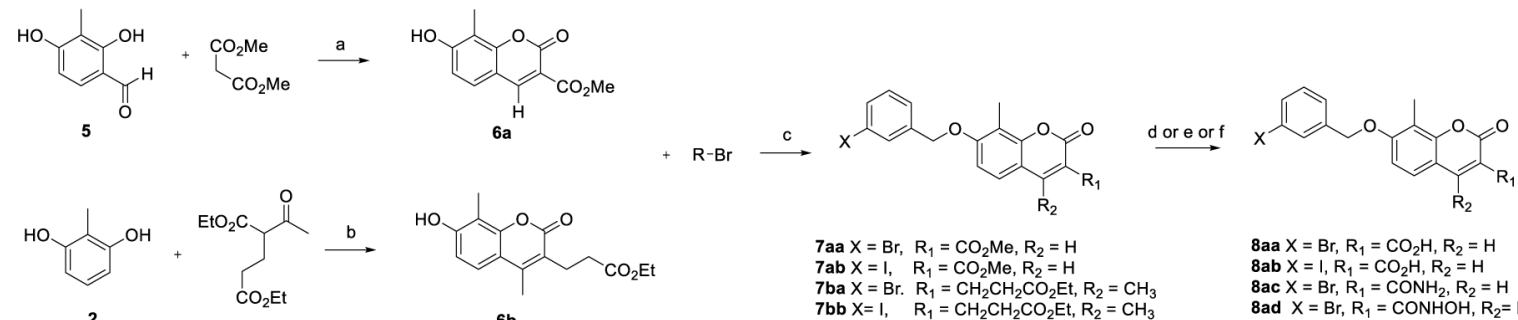

7 aa $X=\mathrm{Br}, \mathrm{R}_{1}=\mathrm{CO}_{2} \mathrm{Me}, \mathrm{R}_{2}=\mathrm{H}$

7 ba X $=$ Br. R $R_{1}=\mathrm{CH}_{2} \mathrm{CH}_{2} \mathrm{CO}_{2} \mathrm{Et}, \mathrm{R}_{2}=\mathrm{CH}_{3}$

7 bb X = I, $\quad \mathrm{R}_{1}=\mathrm{CH}_{2} \mathrm{CH}_{2} \mathrm{CO}_{2} \mathrm{Et}, \mathrm{R}_{2}=\mathrm{CH}_{3}$

8aa $X=\mathrm{Br}_{1} \mathrm{R}_{1}=\mathrm{CO}_{2} \mathrm{H}, \mathrm{R}_{2}=\mathrm{H}$ 8 ab $X=I, R_{1}=C_{2} \mathrm{H}, R_{2}=\mathrm{H}$ 8ac $X=B r_{1} R_{1}=C_{2} \mathrm{CNH}_{2}, \mathrm{R}_{2}=\mathrm{H}$ Bad $X=B r, R_{1}=C O N H O H, R_{2}=H$ 6b

Scheme 2. Synthesis of 8-Methylcoumarin Carboxylate Analogues $\boldsymbol{a}$

${ }^{a}$ Reagents: (a) $\mathrm{H}_{2} \mathrm{SO}_{4}, \mathrm{MeOH}, 57 \%$. (b) $\mathrm{H}_{2} \mathrm{SO}_{4}, \mathrm{EtOH}, 81 \%$. (c) $\mathrm{K}_{2} \mathrm{CO}_{3}$, acetone, reflux,

86-93\%. (d) $\mathrm{NaOH}, \mathrm{MeOH}, 75^{\circ} \mathrm{C}, 44-94 \%$, for 8aa-8bb. (e) $\mathrm{NH}_{3}$ in $\mathrm{THF}, 66 \%$ for 8ac. (f) $\mathrm{NH}_{2} \mathrm{OH}-\mathrm{H}_{2} \mathrm{O}, \mathrm{NaOMe}, \mathrm{MeOH}, 54 \%$ for $\mathbf{8 a d}$. 


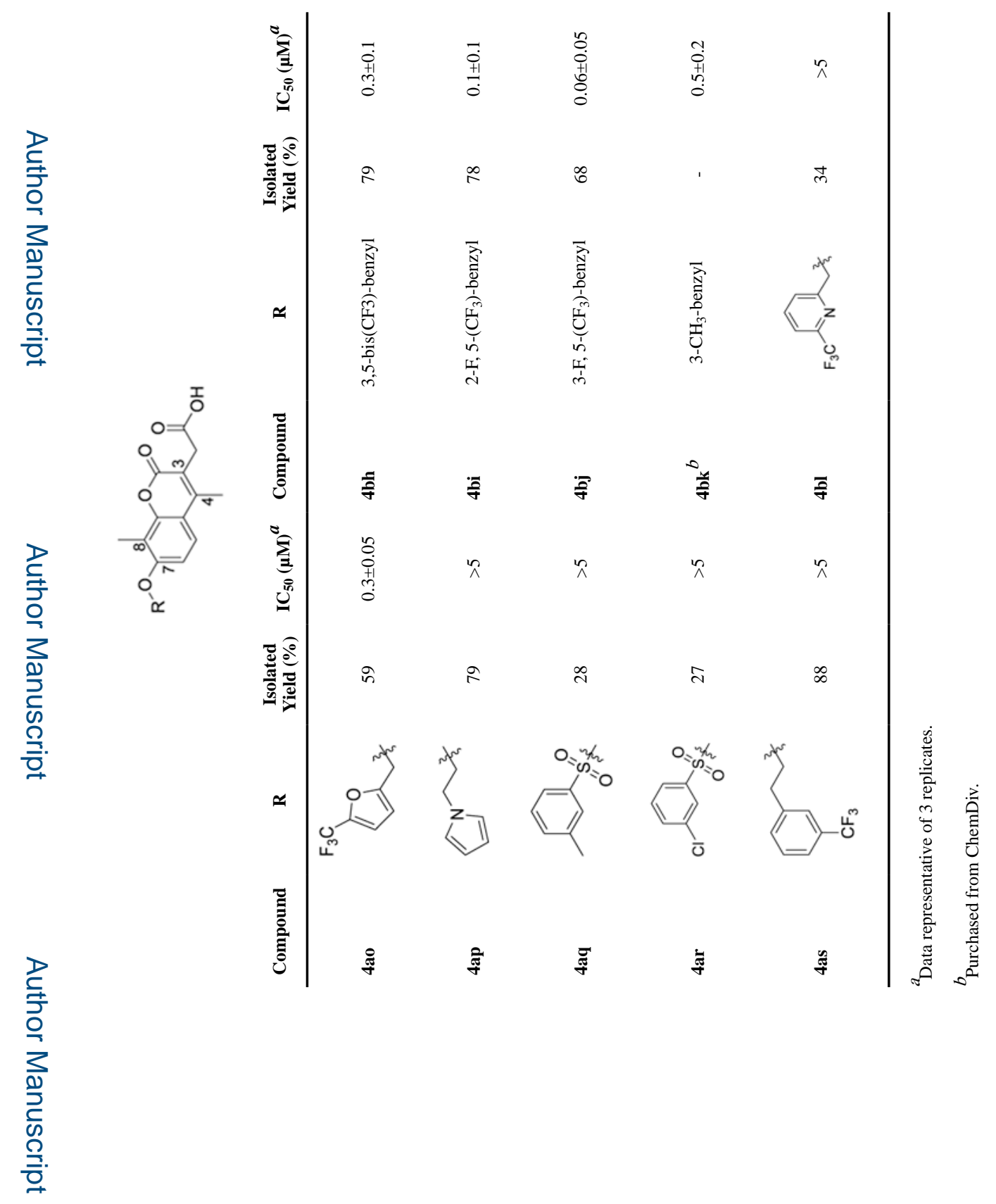

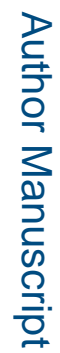

JMed Chem. Author manuscript; available in PMC 2020 February 21. 
Table 2.

Inhibition of DRA (slc26a3-Mediated $\mathrm{Cl}^{-} / \mathrm{I}^{-}$Exchange) by 8aa-8ae, 8ba-8bb

\begin{tabular}{|c|c|c|c|c|c|}
\hline compound & $\mathbf{X}$ & $\mathbf{R}_{1}$ & $\mathbf{R}_{2}$ & $\begin{array}{l}\text { isolated yield } \\
(\%)\end{array}$ & $\mathrm{IC}_{50}(\mu \mathrm{M})^{a}$ \\
\hline $4 \mathrm{ba}$ & $\mathrm{Br}$ & $\mathrm{CH}_{2} \mathrm{CO}_{2} \mathrm{H}$ & $\mathrm{Me}$ & 60 & $0.15 \pm 0.02$ \\
\hline 8aa & $\mathrm{Br}$ & $\mathrm{CO}_{2} \mathrm{H}$ & $\mathrm{H}$ & 44 & $>5$ \\
\hline 8ab & I & $\mathrm{CO}_{2} \mathrm{H}$ & $\mathrm{H}$ & 62 & $>5$ \\
\hline $8 a c$ & $\mathrm{Br}$ & $\mathrm{CONH}_{2}$ & $\mathrm{H}$ & 66 & $>5$ \\
\hline 8 ad & $\mathrm{Br}$ & $\mathrm{CONHOH}$ & $\mathrm{H}$ & 34 & $0.45 \pm 0.1$ \\
\hline 8ae & $\mathrm{Br}$ & $\mathrm{CH}_{2} \mathrm{CONH}_{2}$ & $\mathrm{Me}$ & 57 & $3.3 \pm 0.4$ \\
\hline 8 ba & $\mathrm{Br}$ & $\mathrm{CH}_{2} \mathrm{CH}_{2} \mathrm{CO}_{2} \mathrm{H}$ & $\mathrm{Me}$ & 89 & $>5$ \\
\hline $8 b b$ & I & $\mathrm{CH}_{2} \mathrm{CH}_{2} \mathrm{CO}_{2} \mathrm{H}$ & $\mathrm{Me}$ & 94 & $>5$ \\
\hline
\end{tabular}

${ }^{a}$ Data representative of three replicates. 
Table 3.

Pharmacokinetic Parameters of slc26a3 Inhibitors

\begin{tabular}{clrlr}
\hline compound & route & $\boldsymbol{C}_{\max }(\boldsymbol{\mu} \mathbf{M})$ & $\boldsymbol{T}_{\max }(\mathbf{h})$ & $\mathbf{A U C}(\boldsymbol{\mu} \mathbf{m o l} \mathbf{h} / \mathbf{L})$ \\
4ba & oral & $9.4 \pm 1.8$ & $5.8 \pm 5.1$ & $124 \pm 15$ \\
& ip & $24.3 \pm 3.1$ & $1.5 \pm 0.5$ & $231 \pm 33$ \\
4be & oral & $12.9 \pm 3.7$ & $0.8 \pm 0.2$ & $69 \pm 28$ \\
& ip & $70.2 \pm 5.0$ & $0.8 \pm 0.2$ & $418 \pm 78$ \\
4az & oral & $4.7 \pm 0.5$ & $6.5 \pm 4.8$ & $130 \pm 12$ \\
& ip & $29.1 \pm 2.3$ & $0.5 \pm 0$ & $331 \pm 42$ \\
\hline
\end{tabular}

